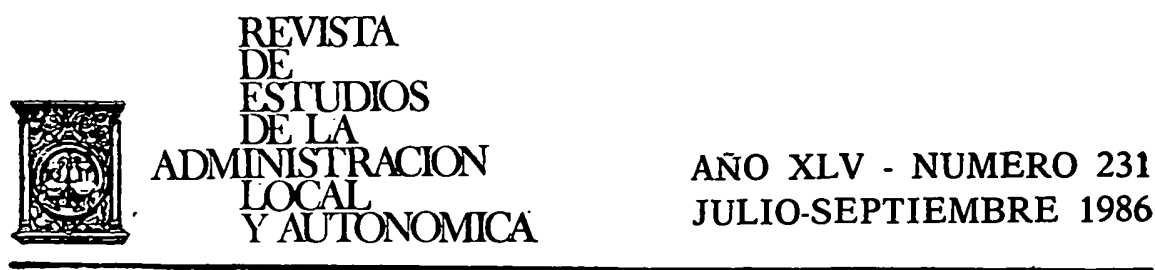

\title{
sumario
}

Págs.

I. SECCION DOCTRINAL $\ldots \ldots \ldots \ldots \ldots \ldots \ldots$

Pedro de Mrguel Garcta: La competencia del Estado y de las Comunidades Autónomas en materia de denominaciones de origen $\ldots \ldots \ldots \ldots \ldots$

José LUIS RIVERo YSERN: Consideraciones generales en torno a la Comarca

Vicente Marfa González-Haba Guisado: La nueva normativa sobre la Función pública y sus derivaciones en el ámbito local.

JuAN MANUEl Alegre Avila: El nuevo sistema de fuentes de los bienes locales, con particular referencia a la regulación de los bienes comunales $\ldots \ldots \ldots \ldots \ldots \ldots \ldots$

José LuIs SÁnchez Díaz: La ejecución normativa del Derecho de la Comunidad Europea por las Comunidades Autónomas.

II. CRONICAS

LEón CoRtiÑas-PELAEz: Notas a propósito de la actualidad de la

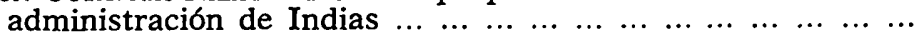

III. JURISPRUDENCIA

Tomás Quintana López y Elena Ferrero Calzada: Obras públi-

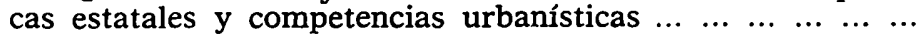

TOMás QUINTANa LOPEZ: Salubridad pública y planificación hi-

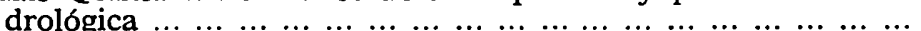


REALA-1986, núm. 231. SUMARIO

REALA-1986, núm. 231. SUMARIO 
REVISTA

$\mathrm{DE}$

\begin{tabular}{c} 
ESTUALS \\
DEIA \\
ADMINISTRACION \\
IOCAL \\
YAUTONOMICA \\
\hline
\end{tabular}

\section{SECCION DOCTRINAL}


REALA-1986, núm. 231. SUMARIO

REALA-1986, núm. 231. SUMARIO 